\title{
COMPORTAMENTO ANATÔMICO DAS VIAS BILÍFERAS DO QUEIXADA (Tayassu pecari - Link, 1795).
}

GILBERTO VALENTE MACHADO ${ }^{1}$; LEA PAULA KIRST ${ }^{2}$; ERUS LUIZ DE SOUZA $^{2}$; GIULIANO GUSTAVO LESNAU ${ }^{2}$

${ }^{1}$ Departamento de Anatomia da Universidade Federal do Paraná/ Campus Palotina.

${ }^{2}$ Estudantes do Curso de Pós-Graduação de Medicina Veterinária.

Objetivando oferecer subsídios ao conhecimento da anatomia comparativa, e em apoio a linha de pesquisa em andamento no Laboratório de Anatomia Veterinária da Universidade Federal do Paraná/Campus Palotina, o presente trabalho visa fornecer dados sobre a anatomia do sistema excretor do fígado dos taiassuídeos, em particular do queixada (Tayassu pecari). Para tal utilizaram-se 20 fígados de queixadas adultos, 12 machos e 8 fêmeas, os quais tiveram as vias bilíferas injetadas, através do ducto colédoco, com solução corada de Neoprene Látex "450", até a total repleção do sistema, em seguida colocados em solução aquosa de formol a 10 \% para sua fixação. Após a dissecação, esquematização e análise, julgase poder concluir que: a) o queixada, diferente de outros suiformes, não apresenta vesícula biliar; b) o ductus choledocus encontra-se, na maioria das preparações (17 vezes), formado pela convergência dos ramus principalis dexter e ramus principalis sinistri, ao passo que nas demais peças, resulta da tríplice união dos ramus principalis dexter, ramus principalis sinistri e ramus lobi quadrati (2 vezes) ou do ramus principalis dexter, ramus principalis sinistri e ramus ventralis lobi dextri (1 vez); c) o sistema do ramus principalis dexter aparece constituído pelo ramus dorsalis lobi dextri, ramus medius lobi dextri, ramus ventralis lobi dextri e ramus processi caudati; d) compõem o sistema do ramus principalis sinistri, o ramus lobi sinistri lateralis, o ramus lobi sinistri medialis, o ramus lobi quadrati (6 vezes) e ramus processi caudati (13 vezes), além de frequentes contribuições provenientes do lobus medialis dextri e, até mesmo, do processi caudati; e) não foram evidenciadas anastomoses pelos critérios de observação utilizados, assim como não ficaram evidentes diferenças estatisticamente significantes em relação aos sexos, ao nível de 5,0\%, ao confrontarem-se os aspectos investigados. 